\title{
Experience-dependent epigenomic reorganization in the hippocampus
}

\author{
Corey G. Duke, ${ }^{1}$ Andrew J. Kennedy, ${ }^{2}$ Cristin F. Gavin, ${ }^{1}$ Jeremy J. Day, ${ }^{1}$ \\ and J. David Sweatt ${ }^{3}$ \\ ${ }^{1}$ Department of Neurobiology, Evelyn F. McKnight Brain Institute, University of Alabama at Birmingham, Birmingham, Alabama \\ 35294, USA; ${ }^{2}$ Department of Chemistry, Bates College, Lewiston, Maine 04240, USA; ${ }^{3}$ Department of Pharmacology, Vanderbilt \\ University, Nashville, Tennessee 37235, USA
}

\begin{abstract}
Using a hippocampus-dependent contextual threat learning and memory task, we report widespread, coordinated DNA methylation changes in CAl hippocampus of Sprague-Dawley rats specific to threat learning at genes involved in synaptic transmission. Experience-dependent alternations in gene expression and DNA methylation were observed as early as $1 \mathrm{~h}$ following memory acquisition and became more pronounced after $24 \mathrm{~h}$. Gene ontology analysis revealed significant enrichment of functional categories related to synaptic transmission in genes that were hypomethylated at $24 \mathrm{~h}$ following threat learning. Integration of these data sets with previously characterized epigenetic and transcriptional changes in brain disease states suggested significant overlap between genes regulated by memory formation and genes altered in memory-related neurological and neuropsychiatric diseases. These findings provide a comprehensive resource to aid in the identification of memory-relevant therapeutic targets. Our results shed new light on the gene expression and DNA methylation changes involved in memory formation, confirming that these processes are dynamic and experiencedependent. Finally, this work provides a roadmap for future studies to identify linkage of memory-associated genes to altered disease states.
\end{abstract}

[Supplemental material is available for this article.]

The formation and maintenance of new memories requires altered gene transcription and subsequent translation of genetic material (Davis and Squire 1984; Alberini 2008). Disruption of these cellular processes has been implicated in multiple cognitive disease states (Abel and Zukin 2008; Jakovcevski and Akbarian 2012). Located at the interface between the cellular environment and the genome, epigenetic mechanisms such as DNA methylation and post-translational modification of histones serve as powerful regulators of genomic architecture and gene expression. These regulatory mechanisms contribute to activity- and experience-dependent processes that control adaptive responses in neuronal systems (Guzman-Karlsson et al. 2014). For example, methylation of DNA at cytosine nucleotides is critical to the function of both developing and adult neurons. DNA methylation is altered by neuronal activity (Guo et al. 2011; Day et al. 2013), is required for synaptic and homeostatic plasticity (Levenson et al. 2006; Feng et al. 2010; Monsey et al. 2011; Meadows et al. 2015, 2016; Yu et al. 2015), and is modified in an experience-dependent manner (Miller and Sweatt 2007; Roth et al. 2009; Miller et al. 2010; Maddox and Schafe 2011; Day et al. 2013; Tognini et al. 2015).

Active DNA methylation and demethylation is required for memory formation and maintenance in multiple brain circuits (Miller and Sweatt 2007; Feng et al. 2010; Miller et al. 2010; Maddox and Schafe 2011; Monsey et al. 2011; Day et al. 2013; Kaas et al. 2013; Rudenko et al. 2013) suggesting a conserved functional role in neuronal information storage across neuronal

\footnotetext{
Corresponding authors: jjday@uab.edu; david.sweatt@vanderbilt .edu

Article is online at http://www.learnmem.org/cgi/doi/10.1101/lm.045112. 117.
}

classes. Moreover, aberrant DNA methylation has also been identified in neurological and psychiatric disease states associated with impaired cognition (Day et al. 2015), such as Alzheimer's disease (De Jager et al. 2014), autism-spectrum disorders (Nardone et al. 2014), schizophrenia (Xiao et al. 2014), and drug addiction (Feng et al. 2015).

Despite the clear necessity for epigenetic and transcriptional changes in memory formation, the precise nature of these phenomena has not been comprehensively explored. Here, we applied whole-genome sequencing tools to systematically characterize memory-related changes in gene expression and DNA methylation status following memory acquisition. Using contextual threat learning, a hippocampus-dependent learning and memory task, we report widespread and coordinated DNA methylation changes in the hippocampus that are specific to threat learning and target genes involved in synaptic transmission and neuronal communication. In addition to providing transcriptome- and DNA methylome-wide maps following behavioral memory formation in the rat, these results shed new light on the dynamic nature of DNA methylation and demethylation in the adult nervous system. We also compare these data sets with previously characterized epigenetic and transcriptional changes in brain disease states to provide a comprehensive resource to aid in the identification of potential memory-relevant transcriptomic and epigenomic targets disrupted in association with pathological states.

(C) 2017 Duke et al. This article is distributed exclusively by Cold Spring Harbor Laboratory Press for the first 12 months after the full-issue publication date (see http://learnmem.cshlp.org/site/misc/terms.xhtml). After 12 months, it is available under a Creative Commons License (AttributionNonCommercial 4.0 International), as described at http://creativecommons. org/licenses/by-nc/4.0/. 


\section{Materials and Methods}

\section{Animals}

Male Sprague-Dawley rats, $\sim 90-120 \mathrm{~d}$ old and weighing 250$350 \mathrm{~g}$, were co-housed in plastic cages in an AAALAC-approved animal care facility on a $12 \mathrm{~h}$ light-dark cycle with food and water available ad libitum. All procedures were performed in accordance with the University of Alabama at Birmingham Institutional Animal Care and Use Committee. All animals were randomly assigned to respective groups, and behavioral conditioning was performed in the light phase of the light-dark cycle.

\section{Behavioral conditioning}

Sprague-Dawley rats were divided into Naïve, Context Only, and Threat Learning groups. Animals in the Threat Learning group were placed in a standard behavioral chamber (Med Associates) for a 7-min behavioral conditioning session (fear conditioning). This session consisted of three electric shocks ( $1 \mathrm{sec}, 1 \mathrm{~mA}$ each) delivered to a metal floor grid every 2 min from the start of the behavioral session. After the final shock, animals remained in the chamber for $1 \mathrm{~min}$. This training paradigm has previously been shown to induce robust and long-lasting contextual fear memory (Miller and Sweatt 2007; Yu et al. 2015). Context Only animals were placed in the same standard behavioral chamber for a 7-min behavioral session in which no footshocks were delivered. Naïve animals were handled at the same time points that Threat Learning and Context Only animals underwent training but were not subjected to other conditioning paradigms prior to biochemical assays. Animals were habituated to handling for $2 \mathrm{~d}$ prior to each learning paradigm. In a group of animals not undergoing biochemical assays, memory performance was tested at $24 \mathrm{~h}$ (long-term memory) and $7 \mathrm{~d}$ (remote long-term memory) after the completion of training. For memory performance tests, animals were returned to the threat learning chamber and allowed to explore the environment for $7 \mathrm{~min}$. We monitored freezing behavior captured using high-speed video recording as readout of fearrelated memory. Fear memory was quantified as the total percentage of time spent freezing. For each animal undergoing sequencing, brains were removed at 1 or $24 \mathrm{~h}$ following behavioral training. The hippocampus was rapidly dissected on ice and subdissected to isolate the whole CA1 of the hippocampus as previously described (Lein et al. 2004).

\section{RNA-seq}

RNA-seq experiments were carried out at the Hudson Alpha Genome Services Laboratory as described previously (Zovkic et al. 2014; Kennedy et al. 2016; Savell et al. 2016). RNA from 5-8 biological replicates per condition (Naïve controls for $1 \mathrm{~h}$ group, $n=4 ; 1$ h Context Only, $n=6 ; 1 \mathrm{~h}$ Threat Learning, $n=8$; Naïve controls for $24 \mathrm{~h}$ group, $n=5 ; 24 \mathrm{~h}$ Context Only, $n=5$; $24 \mathrm{~h}$ Threat Learning, $n=6$ ) was extracted from whole CA1, DNase-treated, and purified (RNeasy, QIAGEN). Two micrograms of total RNA underwent quality control (Bioanalyzer; all RIN values $>8.0$ ), and was prepared for directional, Poly $(\mathrm{A})^{+}$RNA sequencing at Hudson Alpha using NEBNext reagents (New England Biolabs) according to manufacturer's recommendations with minor modifications (including the use of custom library adapters and indexes). The purified RNA underwent sequencing (50-bp paired-end directional reads; $\sim 25 \mathrm{M}$ reads per sample) on an Illumina sequencing platform (HiSeq2000), yielding between 19 and 28 million fragments per sample.

\section{MBD-seq}

Methylated DNA was captured using methyl-binding domain protein immunoprecipitation (MBD-IP; MethylMiner Kit, Invitrogen), using the manufacturer's recommended protocol as described previously (Kennedy et al. 2016; Savell et al. 2016). DNA from 3-4 biological replicates per condition (Naïve controls for $1 \mathrm{~h}$ group, $n=3 ; 1 \mathrm{~h}$ Context Only, $n=4 ; 1 \mathrm{~h}$ Threat Learning, $n=3$; Naïve controls for $24 \mathrm{~h}$ group, $n=3 ; 24 \mathrm{~h}$ Context Only, $n=4 ; 24 \mathrm{~h}$ Threat Learning, $n=3$ ) isolated from the whole CA1 was extracted, RNase treated, and purified (DNeasy, QIAGEN). Of note, $1.5 \mu \mathrm{g}$ of genomic DNA was sonicated to 200-400 bp (Bioruptor Pico, Diagenode). Methylated DNA was collected with recombinant MBD2 protein/biotin complex, which was purified using streptavidin-coated magnetic beads (Invitrogen). DNA sequencing was performed at Hudson Alpha using NEBNext reagents (New England Biolabs) according to the manufacturer's recommendations with minor modifications (including the use of custom library adapters and indexes). DNA libraries were quantified with the Kapa Library Quant Kit (Kapa Biosystems), and underwent sequencing ( $25 \mathrm{M}$ total $50 \mathrm{bp}$ single-end reads) on an Illumina sequencing platform (HiSeq2000), yielding between 19 and 37 million novel reads per sample. Input (non-IP) controls for each group were sequenced under identical conditions for normalization.

\section{RNA-seq data analyses}

Raw paired-end sequenced reads were quality controlled, filtered for read quality (FASTX toolkit, Galaxy), and aligned to the rat Rn5 genome sequence in Galaxy using Tophat v1.4.0 (with custom settings $-\mathrm{p} 8-\mathrm{r}$ 175). Genome-aligned sequenced reads were examined in Seqmonk software release v0.28.0 (Babraham Institute), using Ensembl release v70 gene and feature annotations. For independent Poly $(\mathrm{A})^{+}$samples, transcript expression levels were determined by computing the fragments per kilobase of exon per million mapped reads (FPKM). Replicates were quantile-normalized, grouped by condition, and differential expression compared with the Naïve group was calculated using the DESeq2 algorithm via R plugin in Seqmonk. Multiple comparisons were corrected using a false-discovery rate of 0.05 , and statistical significance was assessed using Student's $t$-tests.

\section{MBD-seq data analyses}

Raw single-end sequenced reads were quality controlled, filtered for read quality (FASTX toolkit, Galaxy) and aligned to the rat genome (Rn5 assembly) in Galaxy using Bowtie. Genome-aligned sequenced reads were examined using SeqMonk (Babraham Institute). CpG coverage and saturation analyses were performed using the program MEDIPS from the Bioconductor open source software package, and each sample was required to have $>90 \%$ signal saturation with a false positive rate of $<20 \%$ to pass quality control. Replicates were quantile-normalized, grouped by condition, and differentially methylated genes (DMGs) were quantified using the EdgeR algorithm (FDR $<0.1$ ). Differentially methylated regions (DMRs) were assessed by dividing the rat genome (rn5) into $500 \mathrm{nt}$ windows using the MEDIPS software package, which allows for the identification of DMRs in the context of CpG density, and these $500 \mathrm{nt}$ regions were quantified using the EdgeR algorithm (FDR $<0.3)$.

\section{Gene ontology and Circos plot}

Gene ontology analysis of gene clusters identified in using this approach was performed using the ClueGO plugin in Cytoscape (Bindea et al. 2009). Enrichment analysis was conducted using a reference set of all genes. Significantly enriched biological process terms (hierarchy level 5-10) containing at least $4 \%$ of genes in each category were identified using a Benjamini-Hochberg falsediscovery rate and $\alpha=0.01$. To further characterize and visualize Threat Learning DEG and DMG alterations, a Circos plot was created using Circos v0.67-7 (Krzywinski et al. 2009).

\section{Results}

\section{Next-generation sequencing of mRNA in the rat hippocampus after learning}

To determine the short and long-term changes in gene expression and CpG methylation in the CA1 for two types of hippocampusdependent learning events, Sprague-Dawley rats were divided into 
Naïve, Context Only, and Threat Learning groups for behavioral conditioning (Fig. 1A). Threat recognition memory was then tested $24 \mathrm{~h}$ and $7 \mathrm{~d}$ after training by measuring the freezing response induced by fear conditioning (Fig. 1B) or subjects were sacrificed 1 or $24 \mathrm{~h}$ after training and the CA1 region of the hippocampus was extracted for analysis (Fig. 1C). Poly(A) ${ }^{+}$RNA was extracted from the left CA1 region, underwent whole-genome RNA-sequencing, and differences between groups in gene expression levels were evaluated.

A

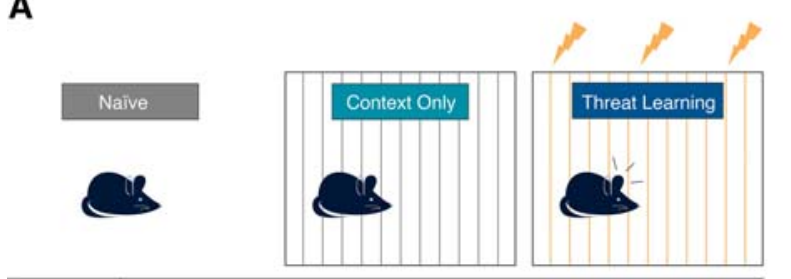

C

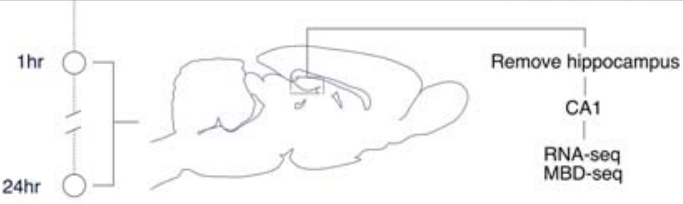

D

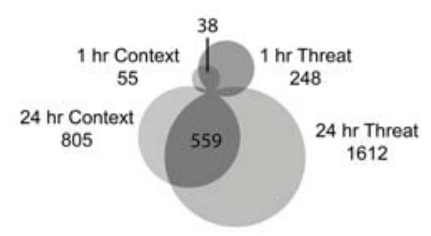

E

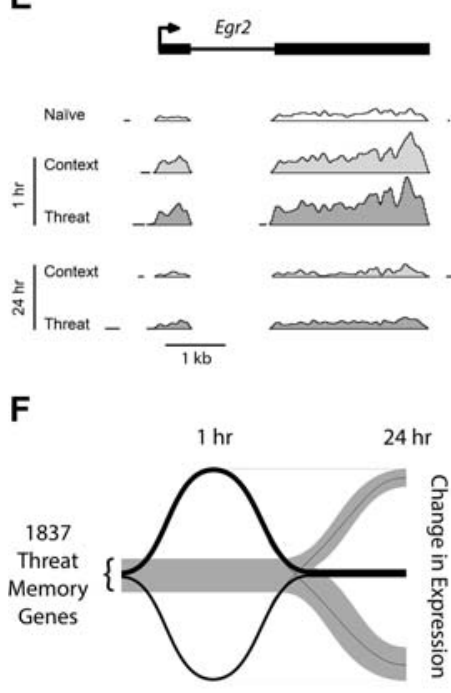

G

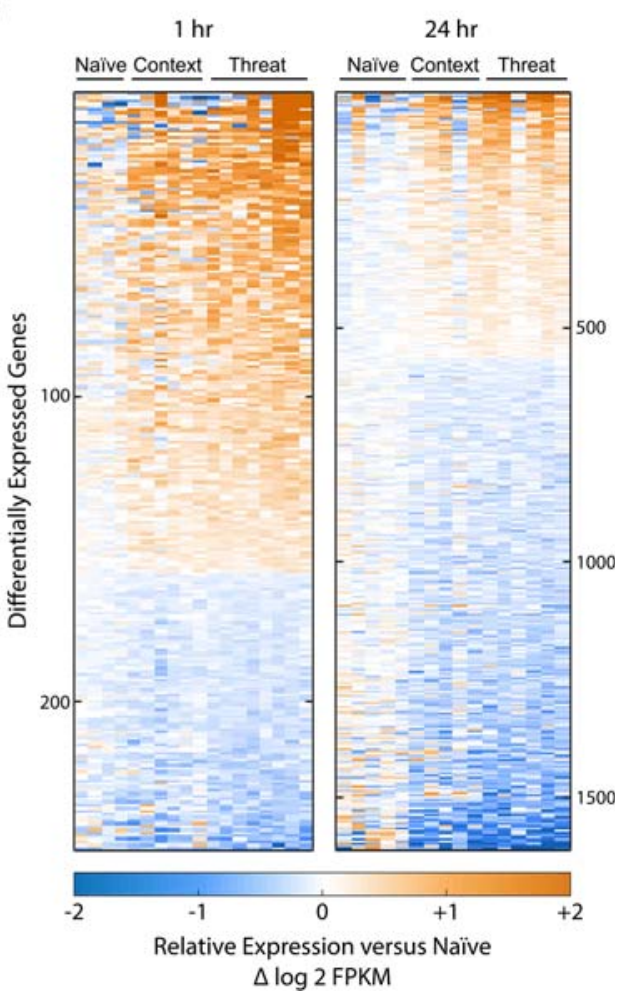

Figure 1. Next-generation sequencing of mRNA in the rat hippocampus after learning. (A) Experimental design. Rats were either kept naïve, introduced to a novel context, or trained using contextual fear conditioning. (B) Threat recognition memory tests at $24 \mathrm{~h}$ and $7 \mathrm{~d}$ after training. (C) RNA and DNA were extracted from the CA1 and DG regions of the hippocampus 1 and $24 \mathrm{~h}$ after training for transcriptomic (RNA-seq) and DNA methylomic (MBD-seq) analysis. (D) Differentially expressed genes (DEGs) after Context Only and Threat Learning compared with Naïve at 1 and $24 \mathrm{~h}$. (E) RNA-seq read density at the immediate early gene Egr2 increases at $1 \mathrm{~h}$ for Context Only and Threat Learning and returns to baseline at $24 \mathrm{~h}$. $(F)$ Genes (1837 total) are differentially expressed at $1 \mathrm{~h}$ (black) and $24 \mathrm{~h}$ (gray) time points after Threat Learning. Thickness of lines is proportional to the number of genes. In general, $1 \mathrm{~h}$ DEGs return to baseline at $24 \mathrm{~h}$, and $24 \mathrm{~h}$ DEGs are not significantly altered at the $1 \mathrm{~h}$ time point, representing two distinct transcriptional waves post learning. (G) Heat map showing relative expression changes at the 1837 Threat Learning DEGs for all replicates.
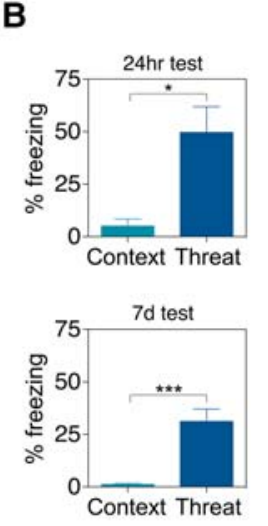
that were differentially expressed following Threat when compared with Context Only at both $1 \mathrm{~h}$ (248) and $24 \mathrm{~h}$ (1612) (Supplemental Table S1). The RNA-seq library from whole CA1 includes RNA from differing types of neurons, excitatory and inhibitory, as well as glia. Thus, the learning-induced transcriptional changes detected here are unbiased toward the participation of each cell type in CA1 function, but genes known to be up-regulated shortly following neuronal activity, such as immediate early genes (IEGs), are still detectable under this methodology. For example, the activity-dependent early growth response gene 2 (Egr2), an IEG up-regulated following LTP induction or $\mathrm{KCl}$ stimulation (Williams et al. 1995; Savell et al. 2016), was significantly up-regulated by threat learning $1 \mathrm{~h}$ after training, but returns to basal levels of expression by 24 $\mathrm{h}$ (Fig. 1E). This trend is true for a vast majority of $1 \mathrm{~h}$ DEGs, returning to basal expression levels by $24 \mathrm{~h}$ when a larger, different wave of DEGs succeeds them. In total, 1837 genes are differentially expressed after Threat Learning, and the most prominent feature of these DEGs is their temporal control. Because nearly all of the 248 DEGs at $1 \mathrm{~h}$ return to baseline at $24 \mathrm{~h}$, DEGs identified from the early and late time points are composed of very distinct gene populations, demonstrating that memory formation and memory consolidation functions of the hippocampus are correlated with separate and unequal waves of gene expression (Fig. 1F). Most DEGs identified at 1 $\mathrm{h}$ after Threat Learning are up-regulated, many being previously known IEGs such as members of the Egr and Fos families and other plasticity-associated genes like $B d n f$ and Nr4a3. Conversely, a majority of DEGs identified at $24 \mathrm{~h}$ after Threat-Learning are down-regulated, including a large number of epigenetic regulators that contribute to histone lysine acetylation (Hdac5, Hdac7, Hdac10, $\mathrm{Kat} 2 \mathrm{a})$, histone lysine methylation (Wbp7, Setdb1, Mll2, Ezh2, Dot1l, Suv42OH2, Kdac5, Kdm4b), and DNA methylation (Dnmt3a, Mbd6, Uhrf1, Mutyh).

Despite the fact that fewer DEGs were detected for the Context Only group, gene expression patterns for both Context Only and Threat Learning groups were remarkably similar across the 1837 Threat Learning DEGs (Fig. $1 \mathrm{G})$. This suggests a high degree of transcriptional overlap between context exposure and threat learning, even 
though one encodes a life-long threat recognition memory and the other does not. It is also noteworthy that the relative change in expression across Threat Learning DEGs at 1 and $24 \mathrm{~h}$ is highly reproducible across individual replicates.

As an additional validation of our RNA-seq approach, we compared our $1 \mathrm{~h}$ Threat Learning DEGs to a published data set (Halder et al. 2016) of CA1 transcriptional alterations following a contextual fear conditioning task at this same time point, finding a highly significant overlap between our data set and theirs (Fisher's exact test, $\left.P<2.66 \times 10^{-11}\right)$.

\section{Sustained gene body methylation changes are associated with Threat Learning, but not Context Only exposure}

To examine epigenetic alterations that occur in the different learning contexts, DNA was collected and purified from CA1 of the right hippocampus at 1 and $24 \mathrm{~h}$ following the Naïve, Threat Learning, or Context Only exposures. Changes in DNA CpG methylation were measured using MBD-seq, which selectively isolates double-stranded CpG methylated DNA fragments from unmethylated, hemimethylated, and hydroxymethylated DNA fragments. Differentially methylated genes (DMGs) were then quantified by comparing gene body CpG methylation in the Context Only and Threat Learning groups against Naïve.

Unlike changes in gene transcription, where both the Context Only and Threat Learning groups exhibited similar alterations, changes in CpG methylation were overwhelmingly associated with Threat Learning and not Context Only. The most profound difference between the groups occurred at $24 \mathrm{~h}$ where 2097 DMGs were detected in the Threat Learning group, while only 3 DMGs were identified in Context Only (Fig. 2A; Supplemental Table S2). These Threat Learning DMGs were reproducible across replicates, and were significantly associated with changes in gene expression at $24 \mathrm{~h}$ (183 genes in both groups; Fisher's exact test, $P<0.0013$ ).

Moreover, DEGs had an inverse relationship between altered expression and methylation at $24 \mathrm{~h}$. This was especially true for hyper-methylated DMGs, where $87 \%$ of overlapping DEGs had downregulated gene expression at $24 \mathrm{~h}$ (Fig. 2B). There was also a significant temporal relationship between Threat Learning DMGs detected at the short-term and long-term time points, with 182 DMGs shared at 1 and $24 \mathrm{~h}$ (Fisher's exact test, $P<2.2 \times 10^{-16}$ ). Thus, these genes

A

C

D
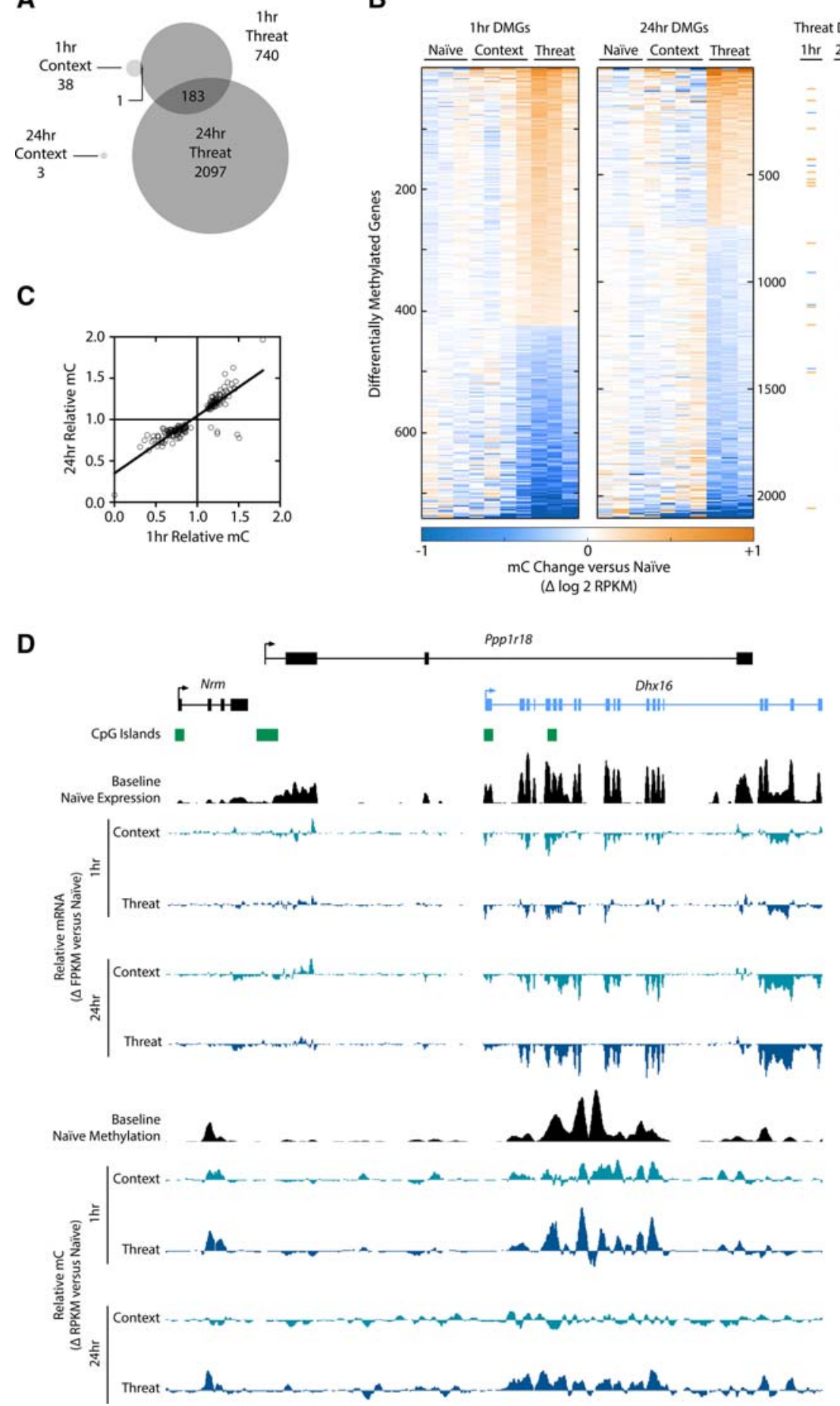

Figure 2. Sustained gene body methylation changes are associated with Threat Learning, but not Context Only exposure. (A) Venn diagram showing the relative group sizes and overlap of DMGs for Context Only exposure and Threat Learning at 1 and $24 \mathrm{~h}$. (B) Heat map showing relative changes in gene body CpG methylation at the 2097 Threat Learning DMGs for all replicates. (C) The correlation of Threat Learning DMGs that are significant at both 1 and $24 \mathrm{~h}\left(\mathrm{R}^{2}=0.08\right)$. (D) Example DMG Dhx16 reveals sustained DNA methylation patterning in Threat Learning but not Context Only exposure; relative changes in RNA-seq and MBD-seq read density for both learning events and time points are shown.

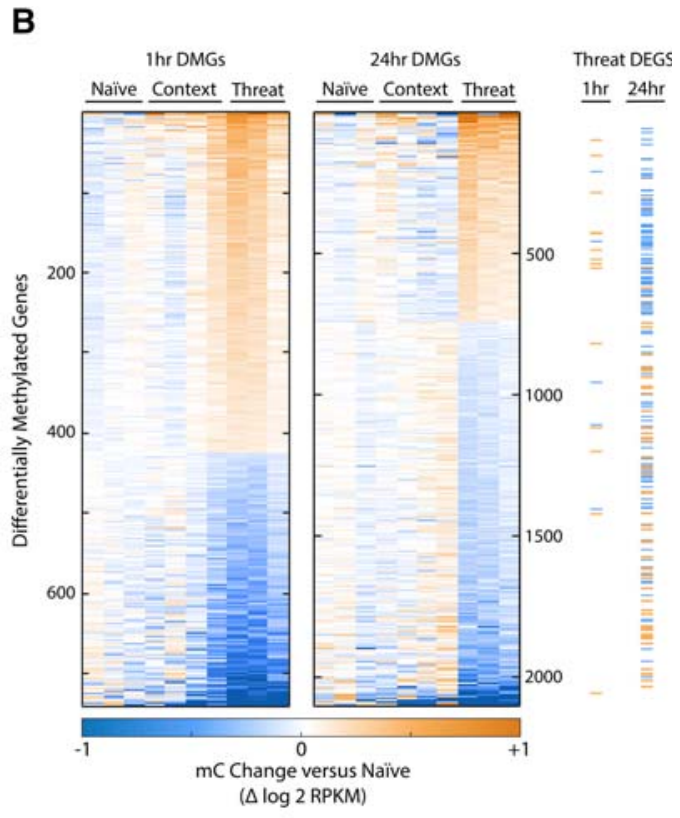

were sustained in their altered methylation status over time, with relative changes in gene body methylation at $1 \mathrm{~h}$ that were strongly correlated to changes at $24 \mathrm{~h}$ (Fig. $2 \mathrm{C}, R^{2}=0.80$ ). 
A representative example of gene body methylation and transcription alterations induced by Threat Learning is the RNA helicase Dhx16 (Fig. 2D). The Dhx16 locus occurs in a gene dense region of chromosome 20 of the rat genome and has two associated CpG islands. Dhx16 mRNA is down-regulated at $24 \mathrm{~h}$ after Context Only exposure and Threat Learning, as shown by the decrease in RNA-seq read density at Dhx16 exons. However, the relation between CpG methylation and Dhx16 expression differs greatly between the two different learning experiences. Threat Learning results in hyper-methylation of the Dhx16 gene at $1 \mathrm{~h}$, and that hyper-methylation is sustained at $24 \mathrm{~h}$. Conversely, Context Only exposure induces a nonsignificant increase in methylation at $1 \mathrm{~h}$, which returns to Naïve levels at $24 \mathrm{~h}$. The connection between DNA methylation and gene expression after Threat Learning, and its stark decoupling in relation to Context Only exposure, is a new finding and suggests a recruitment of DNA methylation mechanisms for some, but not all types of hippocampus-dependent memory.

\section{Increases in DNA methylation occur at gene exons and correlate with reduced gene expression at $24 \mathrm{~h}$}

Gene body methylation is useful in assessing gross differences in methylation status, but it does not provide insight into specific locations where altered methylation occurs within or around gene loci. To determine differentially methylated regions (DMRs) after learning, the genome was divided into small $500 \mathrm{nt}$ regions in which methylation status at particular locations of interest, such as CpG islands, could then be assessed across groups. As with gene body methylation, differential methylation in these smaller regions is overwhelmingly associated with Threat Learning, but not Context Only (Fig. 3A). Threat Learning induces $>5000$ DMRs at both 1 and $24 \mathrm{~h}$ after training, while Context Only is only associated with 17 and 4 DMRs at these respective timepoints (Supplemental Table S3). Additionally, most Threat Learning DMRs are hyper-methylated and occur at CpG rich regions of the genome (Fig. 3B) while DMRs that are hypomethylated occur at CpG-poor regions. Threat Learning DEGs that were down-regulated at $24 \mathrm{~h}$ correlate with 1 and $24 \mathrm{~h}$ posttraining DMGs and DMRs (Fig. 3C); however, Threat Learning DEGs at $1 \mathrm{~h}$ do not. Interestingly, DMRs occurred throughout gene regions, and protein-coding DNA sequence locations were significantly hypermethylated relative to chance (Fig. 3D). DNA methylation differences at $1 \mathrm{~h}$ in Threat Learning DMRs typically became more pronounced and robust in DMRs at $24 \mathrm{~h}$ (Fig. 3E). Hypermethylated DMRs overlapping DEGs at 1 and $24 \mathrm{~h}$ were associated with decreased gene expression (Fig. 3F), consistent with the broad but not universal concept of cytosine methylation being a mechanism for suppressing transcription.

\section{Coordinated alterations in DNA methylation and gene expression following Threat Learning are genome-wide} and overlap with genes altered in cognitive disease models Many different learning-related disease states are associated with altered DNA CpG methylation and altered gene expression (De Jager et al. 2014; Gjoneska et al. 2015). To understand the overlap of our results with the genes altered in a mouse model of one of these disease states (Alzheimer's Disease), a Circos plot was created (Fig. 4) to allow for whole-genome visualization of experiencedependent alterations in $\mathrm{CpG}$ methylation and gene expression. DEGs and DMGs in Threat Learning were found across all chromosomes examined at 1 and $24 \mathrm{~h}$. Only three DEGs at $1 \mathrm{~h}$ were also found in the $1 \mathrm{~h}$ DMG list, and the overlap between these $1 \mathrm{~h}$ gene lists was not significant. However, 183 were found across both the $24 \mathrm{~h}$ DMG and DEG lists, which was a significant overlap between gene lists (Fisher's exact test, $P<$.0013). We then used this composite set of 183 genes found in both the Threat Learning $24 \mathrm{~h}$ DMGs and DEGs gene lists in additional analyses by examining the overlap of this gene list with other data sets. We found significantly more overlap than expected between this gene list and genes altered in a mouse model of Alzheimer's disease (Gjoneska et al. 2015) (Fisher's exact test, $P<3.63 \times$ $10^{-5}$ ), and genes which have their mRNA trafficked to synapses (Cajigas et al. 2012)(Fisher's exact test, $P<1.65 \times 10^{-5}$ ). These analyses demonstrate that genes altered by memory formation are also differentially regulated in a mouse model with memory impairment, and that a significant subset of these genes is associated with the synaptic transcriptome.

To further elucidate the Threat Learning DEGs and DMGs functional characteristics, Gene Ontology term (GO-term) analysis was performed across time points. DEG enrichment analysis revealed the up-regulation of genes involved in the response to cyclic AMP (cAMP) at $1 \mathrm{~h}$, and synaptic function at $24 \mathrm{~h}$ (Fig. $5 \mathrm{~A}-\mathrm{C}$ ). As expected, many of the pathways that were enriched (epidermis development, muscle contraction, etc.) point to gene networks that have not yet been characterized in brain-related function, revealing many novel and dual functions for several genes in the data sets presented here. GO-term analysis of Threat Learning DMGs revealed hypomethylation of genes involved in metabolic processes at $1 \mathrm{~h}$, and genes involved in synaptic transmission and neuronal differentiation at $24 \mathrm{~h}$ (Fig. 6A-C). Interestingly, enrichment of gene networks involved in regulating neuronal differentiation and synapse assembly was found in hypermethylated DMGs at $1 \mathrm{~h}$ rather than hypomethylation in similar networks at $24 \mathrm{~h}$ suggesting time-dependent alterations in methylation status. Given how robust and widespread the alterations in DNA CpG methylation were at $24 \mathrm{~h}$ after Threat Learning $(9.17 \%$ of the genes in the rat genome were differentially methylated), it is important to note that these results suggest the changes in methylation are targeted toward specific functional gene networks.

\section{Discussion}

Our results indicate broad and dynamic regulation of the hippocampal transcriptome in response to behavioral experience. The extensive experience-dependent alterations in the hippocampal cytosine methylome that we observed in this study, correlated with altered gene transcription, is consistent with the emerging view that the epigenome functions at the interface of salient experience and the genome (Mikaelsson and Miller 2011; BakerAndresen et al. 2013; Kundakovic and Champagne 2015). In addition, our findings confirm and extend prior results indicating that chemical modification of DNA plays a dynamic and integral role in the formation and stabilization of long-term memory. The extensive transcriptional and epigenomic alterations that we observe to be correlated with behavioral learning also provide one of the first genome-wide catalogs of hippocampal genes that are targeted for regulation by salient sensory experience.

In our studies, we observed a selective association of dynamic regulation of the hippocampal methylome with Pavlovian associative conditioning versus passive episodic experience (Fig. 2) using a rat behavioral model. This fairly selective association of dynamic regulation of cytosine methylation with Pavlovian conditioning, which arises due to temporally coinciding sensory stimuli (novel place plus footshock in our experiments), was surprising. In our view the most intriguing possibility to explain this observation is a selective role for DNA bidirectional cytosine methylation in associative learning versus episodic spatial 

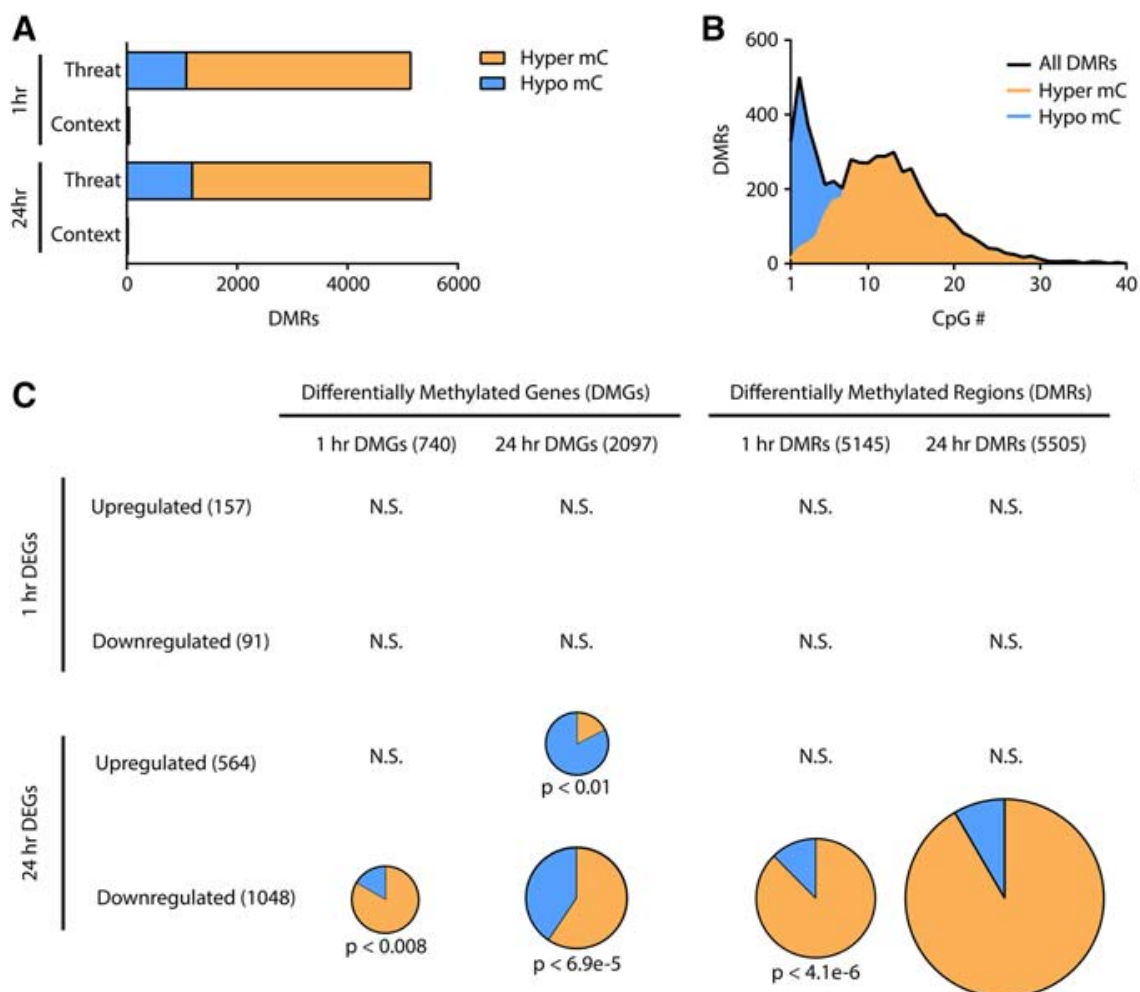

N.S. N.S.

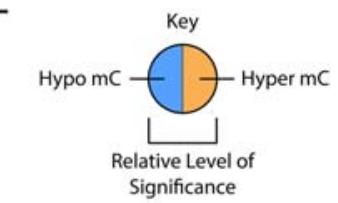

N.S. N.S

N.S. N.S.

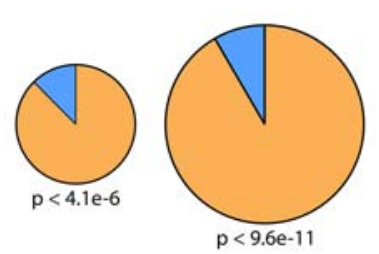

D

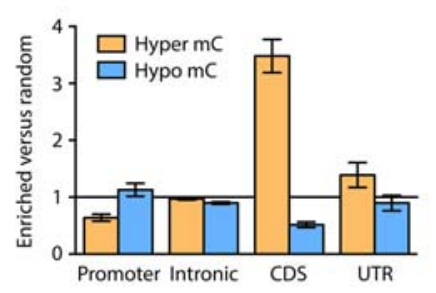

F $\quad 1 \mathrm{hr}$ CDS Hyper mC DMRs $10^{-5} \circ 24 \mathrm{hr}$ CDS Hyper mC DMRs

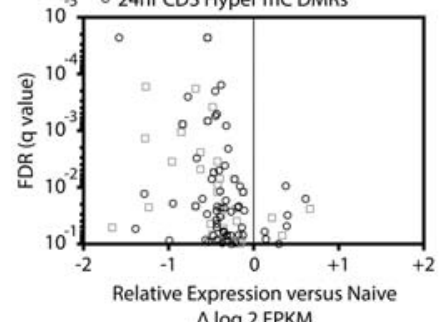

E
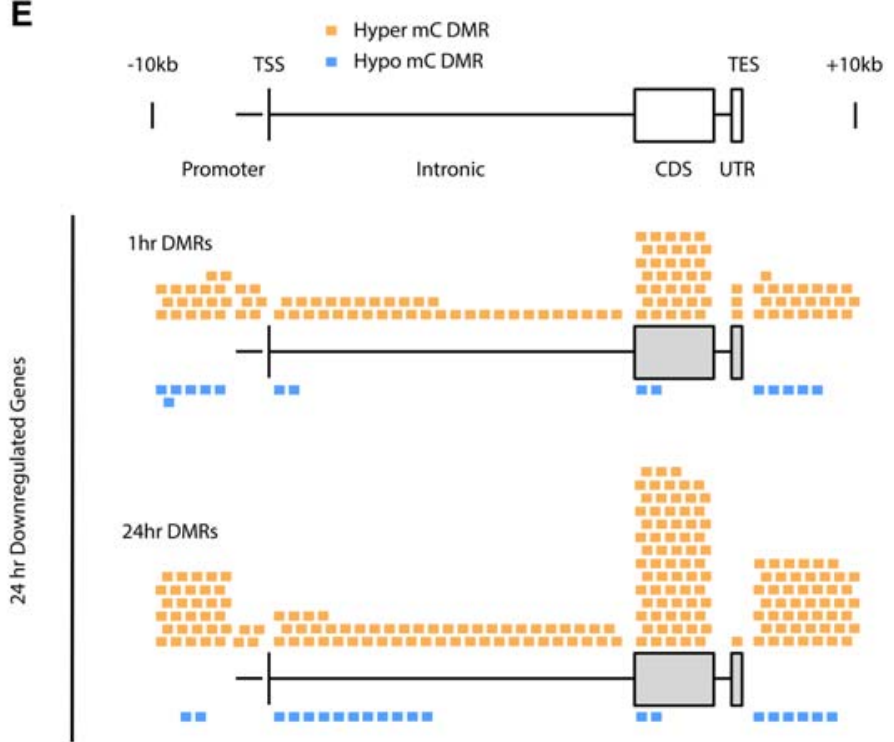

Figure 3. Increases in DNA methylation occur at gene exons and correlate with reduced gene expression at $24 \mathrm{~h}$. ( $A$ ) DMRs are associated with Threat Learning but not Context Only exposure. $(B)$ Threat Learning CpG methylation increases or decreases at DMRs are associated with CpG island density. Depicted are all $550524 \mathrm{~h}$ Threat Learning DMRs in relation to CpG island density. (C) Significant overlaps between DEGs and DMGs or DMRs after Threat Learning occur at $24 \mathrm{~h}$ but not $1 \mathrm{~h}$. (D) $24 \mathrm{~h}$ Threat Learning DMR locations relative to gene features compared with random chance. $\pm 95 \%$ confidence limits. $(E)$ Schematic of Threat Learning DMR locations relative to gene features for down-regulated DEGs. Each brick represents one DMR (1 or $24 \mathrm{~h}$ ) that overlaps with Threat Learning DMGs down-regulated at $24 \mathrm{~h}$, and is placed according to the genomic region in which it is located. The length of each region is representative of its average size across all gene elements in the rat genome. $(F)$ Volcano plot of Threat Learning Hyper mC DMR containing DEGs. The vast majority of Threat Learning DEGs that contain exon hypermethylation were decreased in expression when compared with Naïve controls.

memory. Thus, based on our observations, dynamic regulation of neuronal DNA methylation might selectively subserve associative learning of coinciding events. While this is a speculative interpretation of our results, if this is the case it could indicate a molecular coincidence-detection role for cytosine methylation in the hippocampus, analogous to selective activation of the NMDA receptor upon coincident receptor occupancy and membrane depolarization. Few, if any, specific coincidence-detection mechanisms 


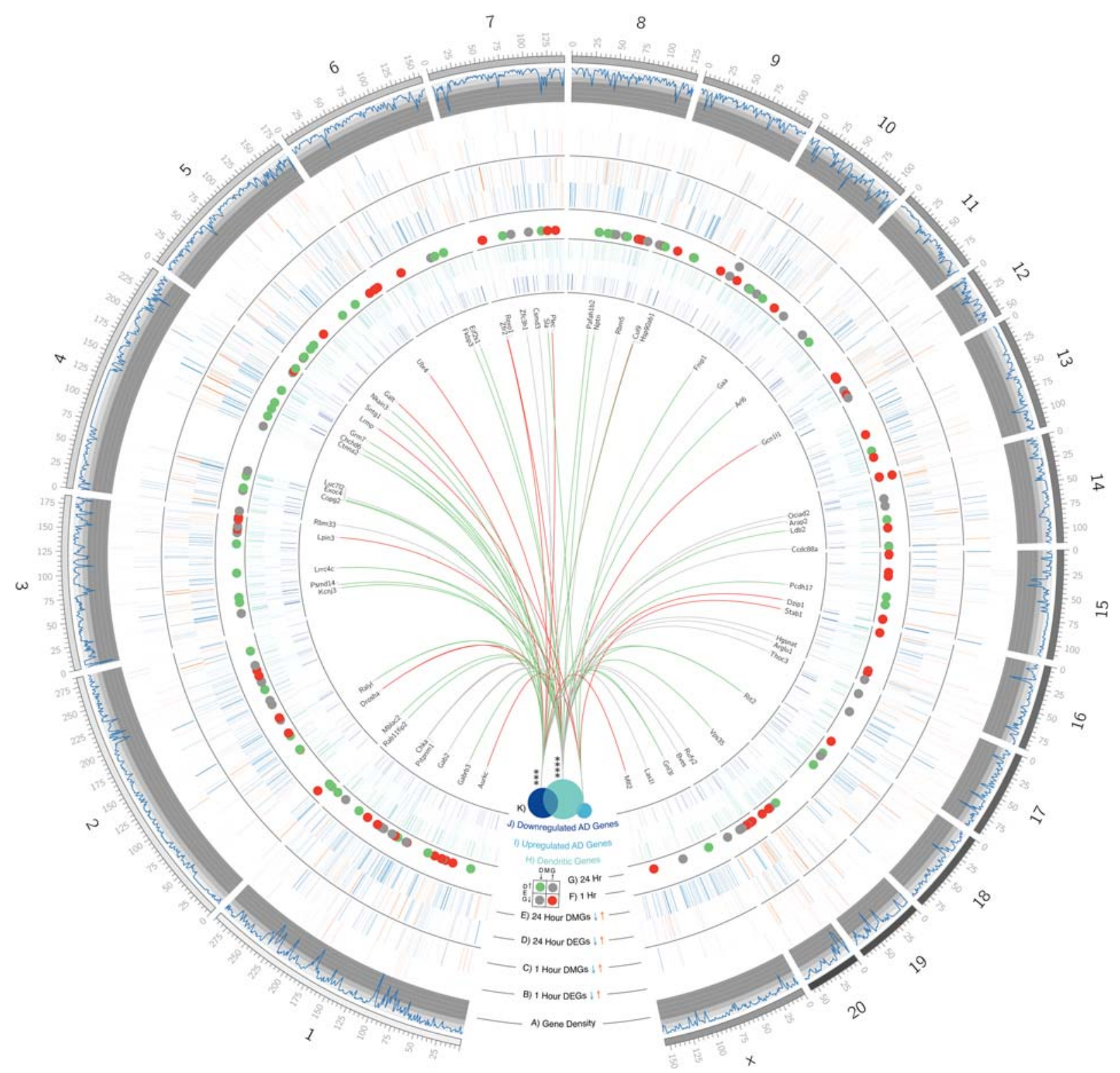

Figure 4. Coordinated alterations in DNA methylation and gene expression following Threat Learning are genome wide and overlap with genes altered in cognitive disease models. CIRCOS plot depicting Threat Learning gene expression and DNA methylation changes. Labels in the outer band represent chromosomal position (tic marks are in $\mathrm{Mb}$ ). (A) Gene density is depicted in the outermost plot, with each axis line representing 10 genes per $1 \mathrm{Mb}$ segment. (B) Threat Learning DEGs at $1 \mathrm{~h}$, with orange representing a significant increase in expression and blue a decrease compared with context Naiive. (C) DMGs at $1 \mathrm{~h}$. (D) DEGs at $24 \mathrm{~h}(E)$ DMGs at $24 \mathrm{~h}$. $(F)$ Genes that were in both the Threat Learning DMG and DEG sets at $1 \mathrm{~h}$, with green circles representing decreased methylation and increased expression, and red representing the opposite. (G) Genes in both the Threat Learning DMG and DEG sets at $24 \mathrm{~h}$. Generally, DEGs with increased expression were associated with decreased methylation, and decreased expression was associated with an increase in methylation. $(H)$ This track represents the genomic location of genes found to have their mRNA trafficked to dendrites in a previous study (Cajigas et al. 2012). The genomic location of genes up-regulated (I) or down-regulated $(J)$ in an Alzheimer's disease mouse model are represented in the next two tracks (Gjoneska et al. 2015). (K) In the center of the CIRCOS plot, we integrate Threat Learning associated genes with these additional data sets, revealing significant associations. Genes that were both differentially expressed and methylated at $24 \mathrm{~h}$, which were also members of the dendritic trafficking or Alzheimer's disease mouse model gene lists, are shown as arcs stemming from their chromosomal position to a circle colored to represent the additional sets they were members of. Arc colors represent genes that were up-regulated and hypomethylated (green), down-regulated and hypermethylated (red), or noncoordinately expressed (gray). The area of each circle represents the number of members found in that group, and the overlap between circles shows the amount of genes that were members of multiple data groups. Significant overlap between the Threat Learning DEG/DMG gene list and these additional data sets was assessed using Fisher's exact test, ${ }^{*} P<0.05,{ }^{* *} P<0.01,{ }^{* * *} P<0.001,{ }^{* * * *} P<0.0001$.

operating at the epigenomic level have been previously described in the CNS, so the underlying molecular basis of how altered methylation might be selectively activated by coincident neural stimuli is mysterious at this point. (Miller and Sweatt 2007; Day et al. 2013; Schafe 2016; Pearce et al. 2017).
However, there are a number of possible alternative explanations for our observation of a selective association of cytosine methylation with contextual fear conditioning versus passive experiential place exposure. The general salience of the environment is presumably increased with associative fear conditioning, 
A

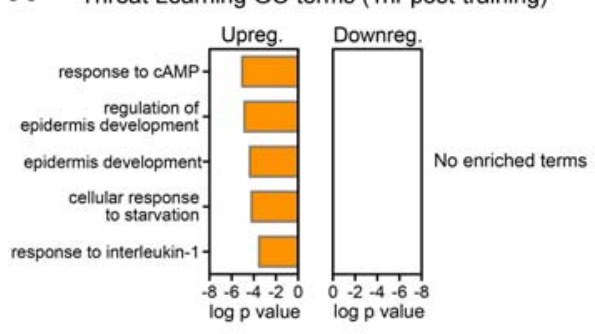

B

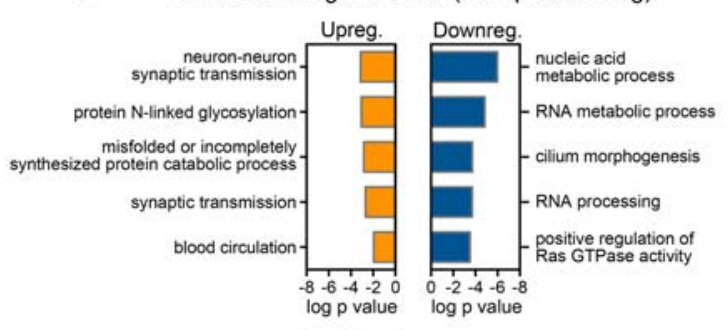

C

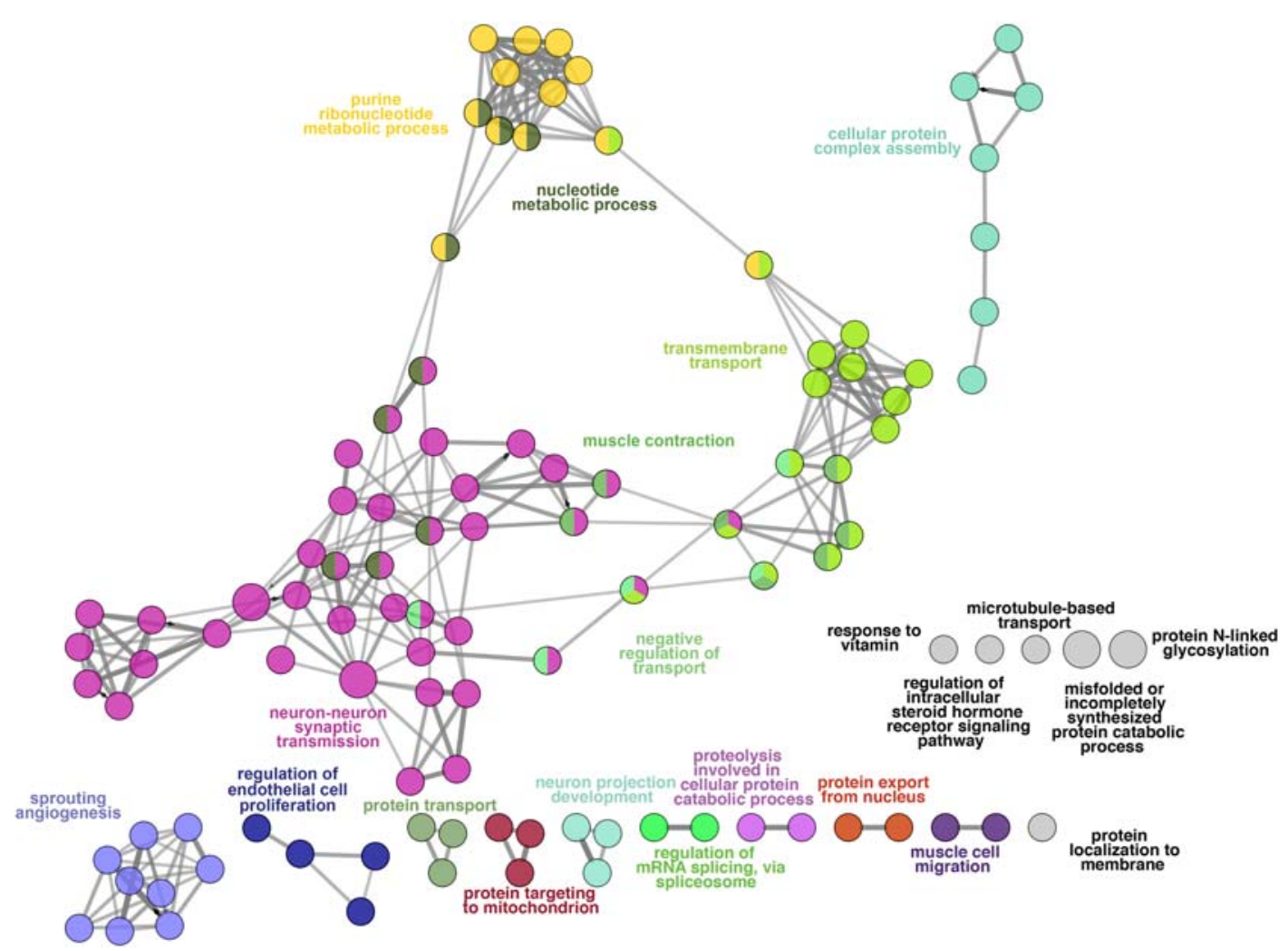

Figure 5. Gene ontology of Threat Learning differentially expressed genes. (A) Gene ontology term enrichment of Threat Learning DEGs $1 \mathrm{~h}$ posttraining indicates pathway enrichment for the response to CAMP in up-regulated DEGs. (B) Gene ontology term enrichment of DEGs $24 \mathrm{~h}$ post-training indicates enrichment for neuron-neuron synaptic transmission in DEGS that are up-regulated and nucleic acid metabolic processes DEGs that are downregulated. (C) Gene ontology cluster node-network diagram of genes up-regulated at $24 \mathrm{~h}$ post-training.

which might lead to more robust molecular changes in the hippocampus, including those in the epigenome. Contextual fear conditioning can trigger life-long memory for the event with a single trial, and thus methylation changes may be correlated with triggering particularly long-lived memories. Other more methodological factors may also be in play. For example, the context-only animals may be experiencing generalized habituation to novel contexts during transportation and handling, diminishing the novelty of the context-only stimulus and attenuating molecular responses. Conversely, the "naïve" animals to which the context-only (and associative conditioning) animals are compared may be experiencing episodic events that are not discernable to the experimenters, which could trigger epigenomic changes in the naïve animals that obscure differences relative to the context-only animals. Further investigation into molecular epigenetic changes in context-only learning will be necessary to distinguish among these various possibilities.

Our data sets revealed that many of the cytosine methylation changes triggered by experience occurred in gene exons, $\mathrm{CpG}$ islands, and around initiation start sites. This observation is in good general agreement with the emerging view that dynamic DNA methylation is not limited to genomic areas around the transcription start site(s), but rather can occur throughout the gene (Xie et al. 2012; Moore et al. 2013). This general observation may reflect a compartmentalization of the "dynamic" methylome from the more static regions of the methylome that are responsible for preserving cell fate, although this idea is quite speculative at present (Day et al. 2013; Sweatt 2013). It also is important to 
A Threat Learning GO terms (1hr post-training)

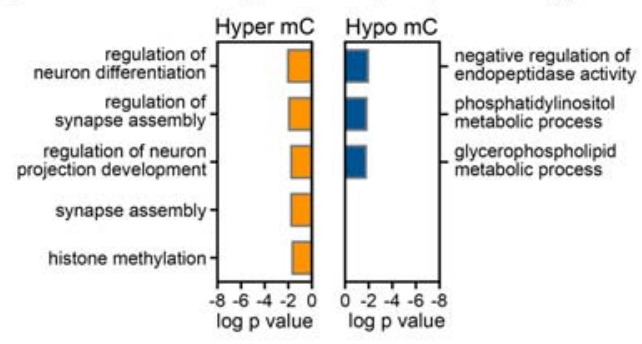

B Threat Learning GO terms (24hr post-training)

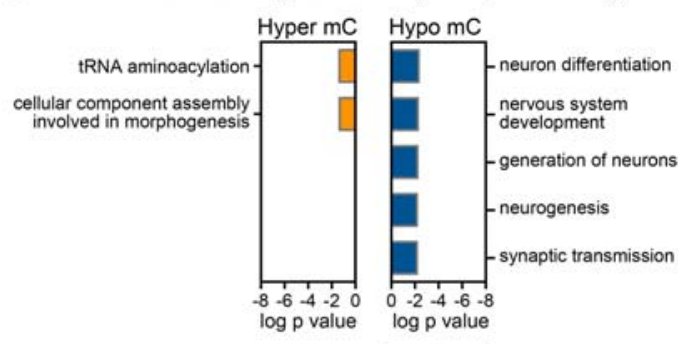

C

Threat Learning GO terms 24hr hypomethylated gene networks

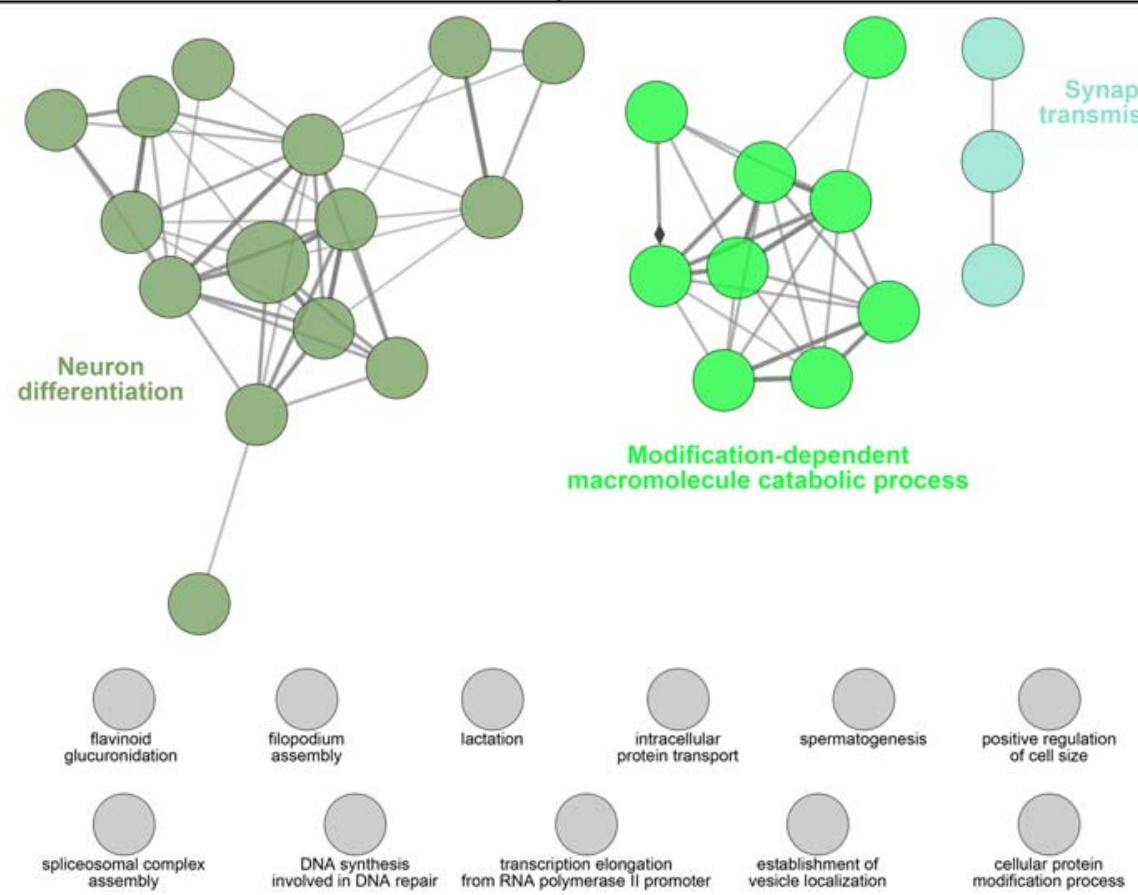

Figure 6. Gene ontology of Threat Learning differentially methylated genes. (A) Gene ontology term enrichment of Threat Learning DMGs $1 \mathrm{~h}$ posttraining indicates enrichment in gene networks involved in the regulation of neuron differentiation, synapse assembly, and endopeptidase activity. ( $B$ ) Gene ontology term enrichment of DMGs $24 \mathrm{~h}$ post-training indicate enrichment for neuron differentiation and synaptic transmission pathways in hypomethylated DMGs. (C) Gene ontology cluster node-network diagram of genes that are hypomethylated at $24 \mathrm{~h}$ post-training.

note in this context that the MBD-seq approach that we used for analyzing methylation is strongly biased toward bi-directional CpG methylation, i.e., cytosines methylated on both strands. This method by-and-large does not detect non-CpG methylation, hemi-methylated CpG's, or cytosine hydroxymethylation.

In this paper, we present an archival data set of NGS-based genome-wide changes in hippocampal cytosine methylation and gene transcription associated with place exposure and contextual fear conditioning in rats. We hope that this data set might be of extensive use to those interested in transcriptional regulation in mammalian memory, allowing investigators to assess using a publicly available data set whether any gene of interest undergoes transcriptional and epigenomic regulation in place exposure and threat recognition training. An obvious constraint in this case is that only two sets of specific training conditions (passive place exposure and context-specific associative fear conditioning) were assessed. However, we propose that our data sets and others of this sort provide highly useful pilot data for many investigators interested in whether a specific gene they are study- ing might be a candidate for experience-dependent epigenomic or transcriptional regulation in the CNS (see also Kennedy et al. 2016). Subsequently, it is important to note that our statistical criteria for assessing whether a specific gene had changes in transcription or methylation had a very high threshold for reaching significance, based on our chosen false discovery rate and correction for multiple comparisons. We would expect based on these considerations that the analysis that we used for purposes of this publication may have led to false-negative results. Thus, any individuals mining our (and others') data sets for pilot data should use appropriate statistical tests oriented toward single comparisons and appropriate $P$-value cutoffs for analyzing significance.

Our data do not directly probe the functional consequences of the changes in hippocampal cytosine methylation that we observe, at either the 1- or 24-h time points. The changes observed at $1 \mathrm{~h}$ after training are presumably associated with memory consolidation, in keeping with prior demonstrations that posttraining infusions of DNA methyltransferase inhibitors block 
consolidation and 24-h long-term memory (Miller and Sweatt 2007; Miller et al. 2008). The changes in methylation observed at $24 \mathrm{~h}$ are perhaps more intriguing, and the potential roles for these changes are essentially unexplored at this point. We speculate that the changes at $24 \mathrm{~h}$ may be perpetuating a state change for the hippocampal neurons in which they occur. Such a persisting change might be involved in biasing particular neurons for subsequent experience-driven transcriptional regulation. In this case, these epigenetic alterations at $24 \mathrm{~h}$ would not be involved in storing memories per se, but rather would be serving a role to influence subsequent hippocampal information processing based on prior experience.

\section{Data availability}

Sequencing data that support the findings of this study have been deposited in Gene Expression Omnibus (GEO) with the accession number GSE95449 (http://www.ncbi.nlm.nih.gov/geo/query/ acc.cgi?acc $=$ GSE95449). All relevant data that support the findings of this study are available on request from the corresponding author (J.J.D.).

\section{Acknowledgments}

The authors' work is supported by NIH grants DA034681 and DA039650 (J.J.D.), MH107254, MH091122, and MH57014 (J.D.S.), HL007473 and GM8007361 (C.G.D.), P20GM0103423 (A.J.K.), DARPA grant HR0011-12-1-0015 (J.D.S.), startup funds from UAB (J.J.D.) and Vanderbilt (J.D.S.), and the Evelyn F. McKnight Brain Research Foundation. The views, opinions, and/or findings contained in this article are those of the author(s) and should not be interpreted as representing the official views or policies of the Department of Defense or the U.S. Government.

Author contributions: A.J.K., J.J.D., and J.D.S. designed the experiments. A.J.K. and J.J.D. executed the experiments and analyzed next-generation sequencing data sets. C.G.D. assisted in analysis of sequencing data sets. All authors contributed to preparation of the manuscript.

\section{References}

Abel T, Zukin RS. 2008. Epigenetic targets of HDAC inhibition in neurodegenerative and psychiatric disorders. Curr Opin Pharmacol 8: 57-64.

Alberini CM. 2008. The role of protein synthesis during the labile phases of memory: revisiting the skepticism. Neurobiol Learn Mem 89: 234-246.

Baker-Andresen D, Ratnu VS, Bredy TW. 2013. Dynamic DNA methylation: a prime candidate for genomic metaplasticity and behavioral adaptation. Trends Neurosci 36: 3-13.

Bindea G, Mlecnik B, Hackl H, Charoentong P, Tosolini M, Kirilovsky A, Fridman WH, Pagès F, Trajanoski Z, Galon J. 2009. ClueGO: a Cytoscape plug-in to decipher functionally grouped gene ontology and pathway annotation networks. Bioinformatics 25: 1091-1093.

Cajigas IJ, Tushev G, Will TJ, tom Dieck S, Fuerst N, Schuman EM. 2012. The local transcriptome in the synaptic neuropil revealed by deep sequencing and high-resolution imaging. Neuron 74: 453-466.

Davis HP, Squire LR. 1984. Protein synthesis and memory: a review. Psychol Bull 96: $518-559$.

Day JJ, Childs D, Guzman-Karlsson MC, Kibe M, Moulden J, Song E, Tahir A, Sweatt JD. 2013. DNA methylation regulates associative reward learning. Nat Neurosci 16: 1445-1452.

Day JJ, Kennedy AJ, Sweatt JD. 2015. DNA methylation and its implications and accessibility for neuropsychiatric therapeutics. Annu Rev Pharmacol Toxicol 55: 591-611.

De Jager PL, Srivastava G, Lunnon K, Burgess J, Schalkwyk LC, Yu L, Eaton ML, Keenan BT, Ernst J, McCabe C, et al. 2014. Alzheimer's disease: early alterations in brain DNA methylation at ANK1, BIN1, RHBDF2 and other loci. Nat Neurosci 17: 1156-1163.

Feng J, Zhou Y, Campbell SL, Le T, Li E, Sweatt JD, Silva AJ, Fan G. 2010. Dnmt1 and Dnmt3a maintain DNA methylation and regulate synaptic function in adult forebrain neurons. Nat Neurosci 13: 423-430.
Feng J, Shao N, Szulwach KE, Vialou V, Huynh J, Zhong C, Le T, Ferguson D, Cahill ME, Li Y, et al. 2015. Role of Tet1 and 5-hydroxymethylcytosine in cocaine action. Nat Neurosci 18: $536-544$.

Gjoneska E, Pfenning AR, Mathys H, Quon G, Kundaje A, Tsai LH, Kellis M. 2015. Conserved epigenomic signals in mice and humans reveal immune basis of Alzheimer's disease. Nature 518: 365-369.

Guo JU, Ma DK, Mo H, Ball MP, Jang MH, Bonaguidi MA, Balazer JA, Eaves HL, Xie B, Ford E, et al. 2011. Neuronal activity modifies the DNA methylation landscape in the adult brain. Nat Neurosci 14: 1345-1351.

Guzman-Karlsson MC, Meadows JP, Gavin CF, Hablitz JJ, Sweatt JD. 2014. Transcriptional and epigenetic regulation of Hebbian and non-Hebbian plasticity. Neuropharmacology 80: 3-17.

Halder R, Hennion M, Vidal RO, Shomroni O, Rahman R-U, Rajput A, Centeno TP, van Bebber F, Capece V, Vizcaino JCG, et al. 2016. DNA methylation changes in plasticity genes accompany the formation and maintenance of memory. Nat Neurosci 19: 102-110.

Jakovcevski M, Akbarian S. 2012. Epigenetic mechanisms in neurological disease. Nat Med 18: 1194-1204.

Kaas GA, Zhong C, Eason DE, Ross DL, Vachhani RV, Ming GL, King JR, Song H, Sweatt JD. 2013. TET1 controls CNS 5-methylcytosine hydroxylation, active DNA demethylation, gene transcription, and memory formation. Neuron 79: 1086-1093.

Kennedy AJ, Rahn EJ, Paulukaitis BS, Savell KE, Kordasiewicz HB, Wang J, Lewis JW, Posey J, Strange SK, Guzman-Karlsson MC, et al. 2016. Tcf4 regulates synaptic plasticity, DNA methylation, and memory function. Cell Rep 16: 2666-2685.

Krzywinski M, Schein J, Birol I, Connors J, Gascoyne R, Horsman D, Jones SJ, Marra MA. 2009. Circos: an information aesthetic for comparative genomics. Genome Res 19: 1639-1645.

Kundakovic M, Champagne FA. 2015. Early-life experience, epigenetics, and the developing brain. Neuropsychopharmacology 40: 141-153.

Lein ES, Zhao X, Gage FH. 2004. Defining a molecular atlas of the hippocampus using DNA microarrays and high-throughput in situ hybridization. J Neurosci 24: 3879-3889.

Levenson JM, Roth TL, Lubin FD, Miller CA, Huang IC, Desai P, Malone LM, Sweatt JD. 2006. Evidence that DNA (cytosine-5) methyltransferase regulates synaptic plasticity in the hippocampus. J Biol Chem 281: $15763-15773$.

Maddox SA, Schafe GE. 2011. Epigenetic alterations in the lateral amygdala are required for reconsolidation of a Pavlovian fear memory. Learn Mem 18: $579-593$.

Meadows JP, Guzman-Karlsson MC, Phillips S, Holleman C, Posey JL, Day JJ, Hablitz JJ, Sweatt JD. 2015. DNA methylation regulates neuronal glutamatergic synaptic scaling. Sci Signal 8: ra61.

Meadows JP, Guzman-Karlsson MC, Phillips S, Brown JA, Strange SK, Sweatt JD, Hablitz JJ. 2016. Dynamic DNA methylation regulates neuronal intrinsic membrane excitability. Sci Signal 9: ra83.

Mikaelsson MA, Miller CA. 2011. DNA methylation: a transcriptional mechanism co-opted by the developed mammalian brain? Epigenetics 6: $548-551$.

Miller CA, Sweatt JD. 2007. Covalent modification of DNA regulates memory formation. Neuron 53: 857-869.

Miller CA, Campbell SL, Sweatt JD. 2008. DNA methylation and histone acetylation work in concert to regulate memory formation and synaptic plasticity. Neurobiol Learn Mem 89: 599-603.

Miller CA, Gavin CF, White JA, Parrish RR, Honasoge A, Yancey CR, Rivera IM, Rubio MD, Rumbaugh G, Sweatt JD. 2010. Cortical DNA methylation maintains remote memory. Nat Neurosci 13: $664-666$.

Monsey MS, Ota KT, Akingbade IF, Hong ES, Schafe GE. 2011. Epigenetic alterations are critical for fear memory consolidation and synaptic plasticity in the lateral amygdala. PLoS One 6: e19958.

Moore LD, Le T, Fan G. 2013. DNA methylation and its basic function. Neuropsychopharmacology 38: 23-38.

Nardone S, Sams DS, Reuveni E, Getselter D, Oron O, Karpuj M, Elliott E. 2014. DNA methylation analysis of the autistic brain reveals multiple dysregulated biological pathways. Transl Psychiatry 4: e433.

Pearce K, Cai D, Roberts AC, Glanzman DL. 2017. Role of protein synthesis and DNA methylation in the consolidation and maintenance of long-term memory in Aplysia. Elife 6: e18299.

Roth TL, Lubin FD, Funk AJ, Sweatt JD. 2009. Lasting epigenetic influence of early-life adversity on the BDNF gene. Biol Psychiatry 65: 760-769.

Rudenko A, Dawlaty MM, Seo J, Cheng AW, Meng J, Le T, Faull KF, Jaenisch R, Tsai LH. 2013. Tet1 is critical for neuronal activity-regulated gene expression and memory extinction. Neuron 79: 1109-1122.

Savell KE, Gallus NV, Simon RC, Brown JA, Revanna JS, Osborn MK, Song EY, O'Malley JJ, Stackhouse CT, Norvil A, et al. 2016. Extra-coding RNAs regulate neuronal DNA methylation dynamics. Nat Commun 7: 12091. 
Schafe GE. 2016. Epigenetics and memory. In Novel mechanisms of memory, pp. 141-160. Springer International Publishing.

Sweatt JD. 2013. The emerging field of neuroepigenetics. Neuron 80: 624-632.

Tognini P, Napoli D, Tola J, Silingardi D, Della Ragione F, D'Esposito M, Pizzorusso T. 2015. Experience-dependent DNA methylation regulates plasticity in the developing visual cortex. Nat Neurosci 18: 956-958.

Williams J, Dragunow M, Lawlor P, Mason S, Abraham WC, Leah J, Bravo R, Demmer J, Tate W. 1995. Krox20 may play a key role in the stabilization of long-term potentiation. Brain Res Mol Brain Res 28: 87-93.

Xiao Y, Camarillo C, Ping Y, Arana TB, Zhao H, Thompson PM, Xu C, Su BB, Fan H, Ordonez J, et al. 2014. The DNA methylome and transcriptome of different brain regions in schizophrenia and bipolar disorder. PLOS One 9: e95875.
Xie W, Barr CL, Kim A, Yue F, Lee AY, Eubanks J, Dempster EL, Ren B. 2012 Base-resolution analyses of sequence and parent-of-origin dependent DNA methylation in the mouse genome. Cell 148: 816-831.

Yu H, Su Y, Shin J, Zhong C, Guo JU, Weng YL, Gao F, Geschwind DH, Coppola G, Ming GL, et al. 2015. Tet3 regulates synaptic transmission and homeostatic plasticity via DNA oxidation and repair. Nat Neurosci 18: $836-843$.

Zovkic IB, Paulukaitis BS, Day JJ, Etikala DM, Sweatt JD. 2014. Histone H2A $\mathrm{Z}$ subunit exchange controls consolidation of recent and remote memory. Nature 515: 582-586.

Received January 23, 2017; accepted in revised form April 12, 2017. 


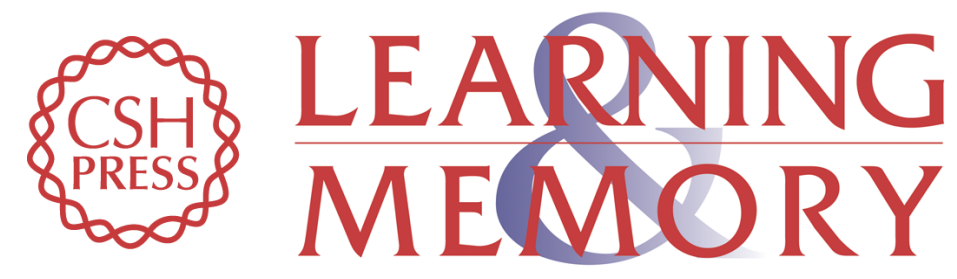

\section{Experience-dependent epigenomic reorganization in the hippocampus}

Corey G. Duke, Andrew J. Kennedy, Cristin F. Gavin, et al.

Learn. Mem. 2017, 24:

Access the most recent version at doi:10.1101/lm.045112.117

\section{Supplemental http://learnmem.cshlp.org/content/suppl/2017/06/07/24.7.278.DC1 Material}

References This article cites 43 articles, 6 of which can be accessed free at: http://learnmem.cshlp.org/content/24/7/278.full.html\#ref-list-1

Creative This article is distributed exclusively by Cold Spring Harbor Laboratory Press for the Commons first 12 months after the full-issue publication date (see

License http://learnmem.cshlp.org/site/misc/terms.xhtml). After 12 months, it is available under a Creative Commons License (Attribution-NonCommercial 4.0 International), as described at http://creativecommons.org/licenses/by-nc/4.0/.

Email Alerting Receive free email alerts when new articles cite this article - sign up in the box at the Service top right corner of the article or click here. 